\title{
Ruptured Cerebral Aneurysms: An Update
}

\author{
Ming Zhong, Bing Zhao, Zequn Li and Xianxi Tan \\ Department of Neurosurgery, The First Affiliated Hospital of Wenzhou Medical College
}

China

\section{Introduction}

A Cerebral aneurysm is an abnormal bulging outward of one of cerebral arteries and is common lesion in the adult population. Cerebral aneurysm occurs in 1 5\% of people which translates to 10 million to 12 million persons in the United States [1,2]Approximately 0.2 to 3 percent of people with an aneurysm suffer from rupture per year. Ruptured aneurysm is the leading cause of subarachnoid hemorrhage (SAH) in $85 \%$ of cases. SAH is a common devastating condition and the age-adjusted annual incidence of SAH 2.0 cases per 100000 population in China[3]. SAH accounts for $5 \%$ of stroke, but the case fatality is as high as $45 \%$ and some patients have significant morbidity among survivors [1,4] Rebleeding is the most imminent danger. The first treatment purpose is therefore complete occlusion of aneurysms and prevention of rebleeding.

Treatment for a ruptured aneurysm includes microsurgical clipping and endovascular coiling. Although microsurgery is the traditional and standard treatment for aneurysms with a high complete obliteration, endovascular treatment has been widely used to treat aneurysm and has displaced surgical clipping in many centers[1, 2, 5-7]. With the development of microsurgical technique and intraoperative monitoring technique, microsurgical clipping still remains a definitive treatment for ruptured cerebral aneurysms $[8,9]$.Now we will review the pathology of ruptured cerebral aneurysm, clinical manifestations for $\mathrm{SAH}$, preoperative evaluation and improvement of surgical techniques.

\section{Pathology of ruptured aneurysm}

Cerebral aneurysms are very common in the population and considered to be sporadically acquired lesions. Acquired factors include atherosclerosis, hypertension and hemodynamic stress. Certain genetic syndromes such as polycystic kidney disease, connective tissue disorders fibromuscular dysplasia, and Marfan's syndrome have also been associated with an increased risk of SAH and support the concept of inherited susceptibility to aneurysm formation[10-12] Aneurysms may also result from congenital defects, weakness of cerebral artery, a decrease in the tunica media, the middle muscular layer of the artery, are thought to have a major role[2].

Most studies on risk of rupture and pathology have been reported, and the mechanism of aneurysmal rupture also is unknown at present[1,4]. A recent meta-analysis yields an annual rupture risk of $0.6 \%$ to $1.3 \%$ of intracranial aneurysms. The Size of aneurysms is the 
most important risk factor for rupture, with smaller risks for smaller aneurysms. Other risk factors are the site, age, female gender. Posterior circulation aneurysms have higher risk of bleeding than anterior circulation[13]. A Statement for healthcare professionals from the Stroke Council, American Heart Association recommends cessation of smoking is reasonable to reduce the risk of $\mathrm{SAH}$, although evidence for this association is not direct[4]. A new study found chronic inflammatory reaction is going on in the aneurysmal wall, and susceptibility of the aneurysm to bleeding is associated with the degeneration of the aneurysmal wall [14]

\section{Clinical classification of SAH}

Aneurysmal SAH is a neurosurgical emergency and devastating event. These symptoms include severe headache, nausea, vomiting, vision impairment, and loss of consciousness. But symptoms are different from every patient with an onset of aneurysm rupture, followed in about one third of the patients by severe confusion or coma. A retrospective study found of 109 patients with SAH, headache was in $74 \%$, nausea or vomiting in $77 \%$, loss of consciousness in $53 \%$, and nuchal rigidity in $35 \%$. As many as $12 \%$ die before receiving medical attention[1].Many patients present with an acute onset of severe headache, often described by patients as the "worst headache of my life" .

Numerous grade systems have been reported for grading the clinical condition of patients with SAH from a ruptured cerebral aneurysm. These include the Hunt and Hess Scale[15] (Table 1), Glasgow Coma Scale, and World Federation of Neurological Surgeons Scale[16] (Table 2), but the current literature remains deficient regarding the grading of patients with SAH. Recently Hunt and Hess scale and World Federation of Neurological Surgeons grading scale are commonly used to describe the neurologic condition on admission and severity of SAH. These grading scales are considered good predictors of ultimate outcome. Computed tomography (CT) of the head can diagnose SAH and be used to describe the amount of blood in the brain. The Fisher grading scale has been shown to correlate with symptomatic vasospasm. Delayed cerebral ischemia (DCI) from vasospasm is an important cause of complications and death after SAH. A new and easy-to-use SAH rating scale accounts for the independent predictive value of subarachnoid and ventricular blood for delayed cerebral ischemia, superior to the Fisher Scale for differentiation between different levels of risk for DCI[17] (Table 3).

\begin{tabular}{ll} 
Grade & Symptoms \\
\hline Grade I & $\begin{array}{l}\text { Asymptomatic or minimal headache and slight nuchal rigidity; } \\
\text { Moderate to severe headache; nuchal rigidity; no neurologic } \\
\text { deficit except cranial nerve palsy. }\end{array}$ \\
Grade III & $\begin{array}{l}\text { Drowsiness, confusion, or mild focal deficit. } \\
\text { Stupor, moderate to severe hemiparesis, and early decelerate } \\
\text { Grade IV }\end{array}$ \\
rigidity and vegetative disturbances. \\
Deep coma, decelerate rigidity; moribund.
\end{tabular}

Table 1. Hunt and Hess grading scale for SAH 


\begin{tabular}{lll}
\hline Grade & Glasgow coma score & Motor deficit* \\
\hline Grade I & 15 & Absent \\
Grade II & 13 or 14 & Absent \\
Grade III & 13 or 14 & Present \\
Grade IV & 7 to 12 & - \\
GradeV & 3 to 6 & - \\
\hline
\end{tabular}

*Excludes cranial neuropathies but includes dysphasia.

Table 2. World Federation of Neurological Surgeons grading system for SAH

\begin{tabular}{|c|c|c|}
\hline Grade & Demonstration & Correlations with DCI \\
\hline Grade 1 & $\begin{array}{l}\text { minimal or diffuse thin SAH without } \\
\text { bilateral IVH }\end{array}$ & low risk \\
\hline Grade 2 & minimal or thin SAH with bilateral IVH & indicating intermediate risk \\
\hline Grade 3 & cisternal clot without bilateral IVH & indicating intermediate risk \\
\hline Grade 4 & cisternal clot with bilateral IVH & high risk \\
\hline
\end{tabular}

Table 3. CT scan scales for SAH and its correlations with DCI

\section{Alternative procedures}

\subsection{Microsurgical clipping and endovascular coiling}

Surgical clipping or endovascular coiling techniques can be used in the treatment of ruptured aneurysms. Most studies on the clipping and coiling of cerebral aneurysms were either small-scale studies or were retrospective studies until the multi-center prospective randomized clinical trial has been reported[6]. The International Subarachnoid Aneurysm Trial (ISAT) study which selected 2143 of $9559 \mathrm{SAH}$ patients for randomization into endovascular or surgical aneurysm treatment found that endovascular coiling treatment produced substantially better patient outcomes than surgical clipping in patients with ruptured aneurysms equally suited for both treatment options[6]. The relative risk of death or severe disability at one year for patients treated by coiling $(15.6 \%)$ was lower than in patients treated by open surgery $(22.6 \%)$.

The results suggest that endovascular coiling is associated with better outcomes at one year than surgical clipping[6, 7]. Unfortunately, most patients in ISAT presented with a favorable clinical grade ( $>90$ percent) and had aneurysms in the anterior circulation ( 97.3 percent) that were smaller than $10 \mathrm{~mm}$ (nearly 95 percent). In general, the incidence of recanalization is higher with coiling and complete aneurysm occlusion is more likely to be achieved with clipping. Long-term follow-up on risks of death, disability, and rebleeding in patients randomly assigned to clipping or endovascular coiling after rupture of an intracranial aneurysm in ISAT, found 24 rebleeding had occurred more than 1 year after treatment and the risk of death at 5 years was significantly lower in the coiling group $(11 \%, 112$ of 1046) than in the clipping group (14\%, 144 of 1041)[9].

Complex intracranial aneurysms are frequently treated with surgical and endovascular methods. These aneurysms are fusiform or complex wide-necked structure, giant size, or 
involvement with critical perforating or branch vessels and are not treated with direct surgical clipping or endovascular treatment. Strategies include surgery followed by endovascular therapy or endovascular therapy followed by surgery[18, 19] . In fact, Medical conditions and severity from an initial SAH influence the selection of treatment. A poor grade aneurysmal SAH may increase the risk of surgical retraction but has less influence on the difficulty of endovascular therapy[20].A large life-threatening hematoma related to ruptured aneurysms may favor a decision to perform open surgery to reduce intracranial pressure by evacuation of the hematoma. Combined treatment involving acute aneurysm coiling and surgical decompression of brain swelling or hemorrhage can also be used successfully. For example, the initial treatment of large clot of blood without mass effect from an aneurysm includes aneurysm clipping with hematoma evacuation, endovascular coiling with hematoma evacuation. In summary, optimal treatment requires availability of both experienced cerebrovascular surgeons and endovascular surgeons working in a collaborative effort to evaluate each case of SAH[1]. In summary, microsurgical treatment with endovascular approach can achieve the best outcomes for patients with ruptured cerebral aneurysms.

\section{Preoperative planning}

Pretreatment planning needs identification of a ruptured aneurysm and delineation of the size and morphologic features of aneurysms. A ruptured cerebral aneurysm commonly leads to SAH or brain hematoma, which is found on a head CT scan. If a CT scan is negative, a ruptured aneurysm is still suspected, a lumbar puncture is performed to detect blood in the cerebrospinal fluid (CSF). Cerebral angiography, computed topographic angiography (CTA) or magnetic resonance angiography (MRA) are commonly used to determine the exact location, size and shape of a ruptured aneurysm before treatment.

MRA in SAH has evolved as the initial test for aneurysm identification and localization over the past decade. The sensitivity of MRA for cerebral aneurysms is only between $55 \%$ and $99.2 \%$, because with aneurysms $5 \mathrm{~mm}$, the sensitivity is $85 \%$ to $100 \%$ and the sensitivity of MRA for detecting aneurysms $<5 \mathrm{~mm}$ drops to $56 \%$ [21, 22]. MRA has practical limitations in the characteristics of the aneurysm neck and its relationship to the parent vessels[1, 23]. MRA takes considerably longer to perform than does CTA and does not replace CT tomography and cerebral angiography to identify the ruptured cerebral aneurysms before treatment[23, 24].

CTA images show cerebral vessels in three-dimensional directions and the vasculature to be visualized relative to the brain and the skull base, facilitating surgical planning. CTA can provide three dimensional images for aneurysm detection, aneurysm location and size[25]. Some studies evaluating CTA in the management of intracranial aneurysms have reported sensitivities ranging from $77 \%$ and $100 \%$ and specificities ranging from $79 \%$ and $100 \%[2,23]$. Among aneurysms detected on CTA and then undergoing surgery, $100 \%$ correlation was observed between CTA and catheter angiography[26]. CTA, as a less invasive alternative to cerebral angiography, is a widely accepted method for detection and characterization of cerebral aneurysms when planning surgical intervention[27].

The sensitivity and specificity of CTA for aneurysm detection depend on radiologist experience, image acquisition, and the presentation of the images. Disadvantages of CTA 
include the need for iodinated contrast dye administration, the possibility of bony artifact that interferes with image quality, and the inability to study small distal vessels. We should have not overestimated the diagnostic accuracy of CT angiography[28] because of the features, the possibility of bony artifact and the inability to study small distal vessels. $74 \%$ patients did not reveal any additional information, when catheter angiography was performed after CTA. Therefore, s small number of neurosurgeons have used these images to perform routine surgery on CTA alone[29].

Digital subtraction angiography (DSA) is currently the standard to document the presence and anatomic features of aneurysms. The three-dimensional cerebral angiography was developed to demonstrate the aneurysm and its relation to other vessels to be assessed in three dimensions, overcoming prior to two dimensional angiography limitations [30]. Actually, CTA is better able to define aneurysmal wall calcification, intraluminal aneurysm thrombosis, orientation of aneurysm with respect to intraparenchymal hemorrhage, and the relationship of the aneurysm with bony landmarks. CTA can also be used to supplement information obtained by catheter angiography[1].

\section{Surgical technique}

Surgical treatment includes aneurysm clipping, aneurysmorrhaphy, trapping, coating, and arterial reconstruction. Carotid ligation was commonly used to treat recently ruptured intracranial aneurysms before 1970. Carotid ligation did not lead to a significant improvement in mortality or rebleeding in the acute period compared with regulated bedrest in the intent-to-treat analysis[31]. Compared with conservative therapy, carotid ligation may produce a decrease in rebleeding; however, the rate of treatment failures of rebleeding plus complications likely exceeds that of direct surgical treatment of the aneurysm[1].

Clipping approach and techniques were introduced by Prof. Yaşargil and have been widely used since 1970s. The current principle of clipping requires microsurgical dissection and clipping of the ruptured aneurysm neck whenever possible. Most patients with anterior or posterior circulation aneurysms, patients in the grades Hunt and Hess IV or V can be treated by clipping in our department[32]. At present it is not necessary to use the large conventional pterional fronto-temporal craniotomies in regular cerebral aneurysm surgery. With developments in visualization of operative microscope, surgical techniques, and the introduction of neuroendoscopy have led to less invasive methods in cerebral base surgery. The keyhole approach has been used for the treatment of a ruptured cerebral aneurysm[33-37].

As we know, the size and location of the cerebral aneurysm is not always proportionate to the extent of brain exposure. Cerebral aneurysms surgery is apt to be treated by the keyhole approach. Keyhole approaches include supraorbital keyhole, the eyebrow keyhole and other keyhole associated with the location of aneurysms. Most supratentorial or basilar tip aneurysms are treated with the supraorbital keyhole approach[34] The concept and technique of the keyhole approach are presented in detail by Prof. Perneczky A [38] The supraorbital keyhole approach offers equal surgical possibilities with less intraoperative accidental rupture and less approach-related morbidity as conventional approaches in the treatment of supratentorial aneurysms. A study comparing the results of minimally invasive 
keyhole craniotomy and standard larger craniotomies found both surgical approaches had reached almost similar morbidity and mortality rates, and overall surgical results[36].

With the development of the endoscope to the microsurgical management, endoscopicassisted microsurgery is an exceptional aid to the surgeon and become part of the operating theatre equipment with no complications[39]. The use of the endoscope to assist the microsurgical clipping of cerebral aneurysm has been reported[40, 41].The rigid endoscope has been increasingly used during aneurysm surgery to plan surgical strategies and verify the regional anatomic features, neck anatomic features and perforators and verification of the optimal clip position. However, it is necessary for the surgeon to be familiar with the endoscope instrumentation and fully prepared for the risks and inconveniences of procedures. Five ways of observing the endoscopic and microscopic images at the same time were introduced[38].Endoscope-assisted microsurgery during keyhole approaches may provide maximum efficiency to clip the cerebral aneurysm, maximum safety for the patient, and minimum invasiveness.

Fusiform and dolichoectatic aneurysms are often not treated with direct clipping and require alternative surgical strategies such as the wrapping technique, arterial reconstruction. These aneurysms are commonly located on the middle cerebral artery, carotid ophthalmic. Clip-wrap techniques for the treatment of fusiform aneurysms seem to be safe to prevent rebleeding and represent an improvement with a low rate of acute or delayed postoperative complications[42]. In some lesions of giant or large internal carotid artery-ophthalmic artery aneurysm which cannot be trapped, proximal and distal occlusion (trapping) is the most effective strategy, however, occlusion of parent arteries has a high incidence of transient complications and may lead to ischemia [1]. Many patients with proximal parent artery occlusion with surgical clips or endovascular techniques will be consider necessary to perform brain cerebral blood flow alteration or an extracranialintracranial arterial bypass. Bypass technique is an important and increasing aspect of these alternative treatments.

Temporary vascular occlusion has been frequently used during aneurysm surgery prevent intraoperative rupture of large or difficult-to-approach aneurysms. The length of time of temporary clips is dependent on the capability of a low brain perfusion. In selected patients with giant aneurysms, particularly of the basilar artery, deep hypothermia with circulatory arrest under cardiopulmonary extracorporeal circulation has been shown to be an acceptable technique[43]. However, there is no reliable method of predicting the possibility of ischemia due to extended regional circulatory interruption by the temporary clipping technique during surgery.

\section{Intraoperative monitoring method}

The routine monitoring methods includes continuous EKG monitoring, and frequent determinations of blood pressure, electrolytes, fluid balance, in many centers. These monitoring and intervention may belong to neuroanesthetic management. In addition to microsurgical dissection and clipping aneurysm, correct intraoperative assessment of aneurysm occlusion, perforating artery patency, and parent artery reconstruction are possible in all patients with ruptured aneurysms. At present there are no reliable and standard method to assess regional anatomic features, verification of the optimal clipping 
and other ischemia events after surgery. The assisted neuroendoscope technique, the intraoperative microvascular doppler probe (IMD)[44, 45] [42] and fluorescence angiography [46] have been used intraoperative microsurgical treatment of cerebral aneurysms.

Microvascular doppler sonography with a $20-\mathrm{MHz}$ probe (1-mm diameter) was used in 1990s[44]before and after clip application, to confirm the obliteration of aneurysms. Now many studies showed IMD is a safe, instantaneous, effective, reliable method instead of moreover intraoperative angiography for the surgical treatment of aneurysms. IMD is also used for assessment of a blood flow reduction for adjusting the clip placement[45].Intraoperative angiography (IOA) has proven to be a safe and effective adjunct to cerebral aneurysms surgery[47]. Although an argument for routine use of IOA exists during cerebral aneurysm surgery and substantial practice variation exists regarding use of this modality in different centers, including use of IOA routinely, selectively, or rarely. IOA should be standard in cerebral aneurysm surgery[42].Fluorescence angiography method is a microscope integrated intraoperative near-infrared indocyanine green angiography (ICG) technique and microscope-integrated light source containing infrared excitation light illuminates the operating field. ICG provides real-time information of the cerebral vasculature about aneurysms[46, 48] Summarily the intraoperative monitoring and vascular imaging methods compared were complementary rather than competitive in nature method.

The occurrence of brain ischemia during surgery due to temporary arterial occlusion or incorrect placement of the clip is a major complication of aneurysm surgery. At present, no method exists to predict the possibility of ischemia cased by aneurysm surgery. A study reported brain tissue oxygen concentration $(\mathrm{PtiO}(2))$ was monitored during surgery of middle cerebral artery (MCA) aneurysm with SAH and found intraoperative monitoring of $\mathrm{PtiO}(2)$ may be a useful method of detection of changes in brain tissue oxygenation during MCA aneurysm surgery for detection of changes in brain oxygenation due to reduced blood flow, as a predictor of ischemic events[49] .

\section{Complications}

\subsection{Rebleeding}

Rebleeding remains a serious consequence of aneurysmal SAH, with a case fatality rate of $70 \%$, and is currently the most treatable cause of poor outcomes[1]. Previous studies delineated the re-bleedings in the first days were thought to be related to the unstable nature of the aneurysmal thrombus. The incidence of rebleeding in unoperated patients is greatest in the first 2 weeks. In the prospective Cooperative Aneurysm Study [50], the rate of rebleeding was $4 \%$ on the first day after SAH and then constant at a rate of $1 \%$ per day to $2 \%$ per day over the following 4 weeks. Recent studies found that all preoperative rebleeding occurred within 12 hours of initial SAH and $70 \%$ of ultraearly rebleeds occurred within 2 hours of initial SAH[51, 52].A large retrospective study reported a rebleeding rate of $6.9 \%$ after admission but no relationship to blood pressure[53].

Although older studies demonstrated an overall negative effect of antifibrinolytics, recent evidence suggests that early treatment with a short course of antifibrinolytic agents combined with a program of early aneurysm treatment followed by discontinuation of the 
antifibrinolytic and prophylaxis against hypovolemia and vasospasm may be reasonable (Class IIb, Level of Evidence B). Antifibrinolytics, and other medical measures alone are not enough to prevent rebleeding after SAH except early treatment of ruptured cerebral aneurysms[1].

Procedural efficacy for treatment of a cerebral aneurysm is determined by the rebleeding and the residuals and recurrences of the treated aneurysm. One study reported all rebleeding occurred in the first 12 months after treatment and overall rebleeding with endovascular treatment was somewhat more common than with surgical treatment[54]. Case reports have demonstrated that even when aneurysms appear to be completely occluded after surgery, rebleeding may occur later[55]. However, the majority of hemorrhages after treatment reported in patients with postoperative angiography have occurred in incompletely occluded aneurysms.

\subsection{Cerebral vasospasm}

Cerebral vasospasm is the most common cause of death and disability after aneurysmal $\mathrm{SAH}$. In one half of patients, vasospasm is manifested by the occurrence of a delayed neurological ischemic deficit. $15 \%$ to $20 \%$ of such patients suffer stroke or die of vasospasm despite maximal therapy[1]. Vasospasm leads to additional artery lumen narrowing, impaired vascular reactivity, a fall in cerebral blood flow which causes ischemia and following infarction. The development of a new focal deficit or the obvious symptoms in comatose unexplained by hydrocephalus or rebleeding, is the first objective sign of symptomatic vasospasm.

Monitoring for vasospasm typically include the clinical neurologic exams, serial measurement of blood flow and catheter angiography. Detection of signs of vasospasm is particularly difficult in poor grade patients. Many centers, including our department, rely on cerebral angiography for the diagnosis of vasospasm. However, the American Academy of Neurology Expert Committee believes the use of TCD on the basis of the fact that although sensitivity and specificity are quite variable and depend on the vessel of interest, severe spasm can be identified with fairly high reliability[56].Recently perfusion computed tomography, diffusion weighted magnetic resonance imaging, and single photon emission computed tomography (SPECT) in detecting vasospasm is under investigation[57]. However, the effect of microsurgical treatment on incidence of vasospasm is not exactly known.

The management of vasospasm involves medical drugs, aggressive volume expanse interventions and hemodilution. Calcium channel blockers, particularly Nimodipine (oral) $60 \mathrm{mg}$ every four hours reduces the risk of poor outcome and secondary ischemia related to aneurysmal SAH (Class I, Level of Evidence A)[5].The use of triple-H therapy (hypervolemia, hypertension and hemodilution) induces hypertension and improves cerebral blood flow, and then improves patients' clinical symptoms. Therefore, Volume expansion therapy becomes a mainstay in the management of cerebral vasospasm[5]. However, recent studies found there was no any difference between the prophylactic volume expansion and hyperdynamic therapy group and the normovolemic therapy group $[58,59]$. Moreover, the initiation of prophylactic volume expansion is associated with significant risks, including the possibility of cardiac failure, electrolyte abnormality, cerebral edema. The prophylactic hemodynamic therapy needs further study before it can be commonly used[60]. 
Endovascular techniques frequently play a role in the aggressive treatment of vasospasm, including transluminal angioplasty, balloon angioplasty, and intra-arterial infusion of vasodilators [61], Spastic cerebral vessels are dilated mechanically via microcatheters. The theoretical goal of balloon angioplasty is to increase the CBF distal to the area of stenosis. However, interventional procedures have their unique associated risks and the optimal timing of angioplasty in relation to medical therapy is uncertain[62].

With microcatheter technology improving and superselective techniques having advanced over the last decade, it has become possible to selectively catheterize third- and fourth-order cerebral vessels and to administer high doses of vasodilators such as papaverine into vessels that cannot be treated with balloon angioplasty[63]. The doses of papaverine reported in the literature are infused at a concentration of $3 \mathrm{mg} / \mathrm{mL}$ at 6 to $9 \mathrm{~L} / \mathrm{min}$ for a total dose of up to $300 \mathrm{mg}$ per vascular territory[64]. Alternatively, cerebral angioplasty and/or selective intraarterial vasodilator therapy may be reasonable after, together with, or in the place of triple-H therapy, depending on the clinical scenario (Class IIb, Level of Evidence B)[1]. Despite recent advances in the treatment of the vasospasm of aneurysmal SAH, few effective treatments exist, and further research is needed.

\subsection{Postoperative image evaluation}

Surgery claims to exclude aneurysms completely from the circulation and rates of aneurysms rupture is significantly decreased relative to the natural history of the lesions. However, Aneurysm residuals and recurrences are not uncommon after microsurgery. A risk of rupture is still present even after surgical clipping. Rates of aneurysm residuals are not negligible, ranging from $3.8 \%$ to $8 \%$.[65]. In a small number of patients treated by surgery, the aneurysm is incompletely clipped and has a risk of rupture and regrowth. Case reports and series have found that even when aneurysms appear to be completely occluded after surgery, recurrence and rupture may occur later. The incidence of recurrent aneurysms after complete clipping was approximately $0.02 \%$ per year; aneurysms recurred after 13.3 years on average with 25 years the longest duration from initial clipping to recurrence[66] . Repeat craniotomy may be performed to prevent the rebleeding.

Follow-up imaging provides an opportunity to identify incompletely treated aneurysms by the conventional DSA. Computed tomography angiography (CTA) is a time and cost saving investigation for postoperative evaluation of clipped cerebral aneurysm patient[67]. In one study up to $85 \%$ of postoperative CTA images were of excellent quality with absent or minimal artefacts in $81 \%$ and seem adequate to detect small aneurysm remnants[68]. Threedimensional DSA also allows us to detect more residual aneurysms after surgical clip placement than what is indicated in the existing literature, the conventional DSA[69].Threedimensional DSA may provide baseline data for the long-term follow-up of postsurgical aneurysms[70].

\section{Outcome}

In a population-based study by Broderick et al, the 30-day mortality rate among all patients who suffered from $\mathrm{SAH}$ was $45 \%$, with the majority of deaths occurring in the first days after SAH[71]. The prospective, randomized trial to date comparing surgery and 
endovascular techniques is ISAT, which selected 2143 of 9559 SAH patients for randomization into endovascular or surgical aneurysm treatment Evaluation at one year demonstrated mortality rate was $10.1 \%$; greater disability rate was $21.6 \%$ in surgical patients $[6,7]$. The prognosis for a patient with a ruptured cerebral aneurysm treated by microsurgery depends on brain injury severity from initial bleeding, the extent and location of the aneurysm. The most significant factors in determining outcome are GCS and increasing age. Generally patients with Hunt and Hess grade I and II on admission can anticipate a good outcome, and Hunt and Hess grade IV and V have a poor outcome, death, or permanent severe disability.

\section{Expert suggestions}

In general, all patients with aneurysmal SAH frequently get CTA and selective threedimensional DSA to plan the individual therapeutic strategy in our hospital: microsurgical, endovascular. CTA has advantages of rapid image acquisition and its widespread availability, which can make it suitable for critically ill patients. Patients with lifethreatening hematoma and with suspected the ruptured aneurysms only receive CTA, which are used for emergency surgery for clipping. Postoperative angiography is usually recommended and performed, including CTA and three-dimensional cerebral angiography. Three-dimensional angiography is the best method for evaluation of aneurysm residuals or recanalisation, providing detailed information from all different angles.

\section{Explicative cases}

Case 1. A 46-year-old woman with SAH was diagnosed with a ruptured anterior communicating artery aneurysm using CTA and DSA, and then treated with microsurgical clipping. $\mathrm{C}$ and $\mathrm{D}$ : The aneurysm neck was completely clipped by the pterional approach.

Case 2. A 52-year-old woman was diagnosed with a brain hematoma due to a ruptured middle artery aneurysm on admission and received emergency open surgery after CTA.

Case 3. Postoperative 3D-CTA was performed 10 days after surgical clipping and showed the complete occlusion of a posterior communicating artery aneurysm.

Case 4 Postoperative 3D-DSA showed two aneurysms on the posterior communicating and A1 segment of anterior cerebral artery were clipped completely.

\section{Conclusion}

Aneurysmal SAH is a common and devastating condition, with a high mortality and morbidity rate. Despite recent advances in microsurgical treatment, endovascular coiling and preoperative management, the outcome of ruptured aneurysm remains poor. Although microsurgical treatment and intraoperative motoring procedures are developed rapidly, outcome of patients treated by microsurgery involves many factors: ruptured severity, Hunt and Hess grade, aneurysm location, size and characteristics. Decisions about microsurgery, the surgical approach, and specific technical adjuncts must be based on the individual clinical setting. 


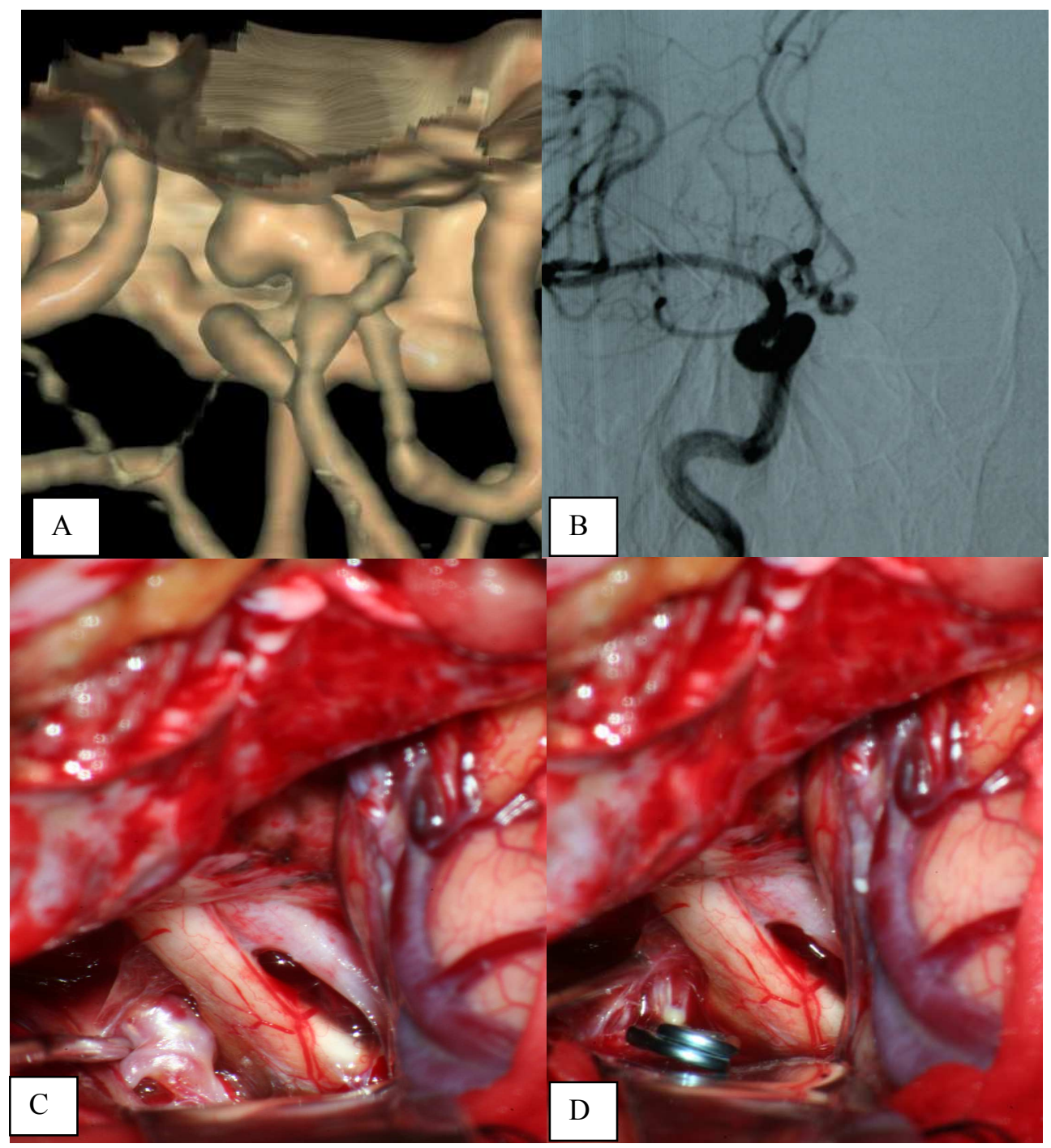

Fig. 1. Case 1: A and B: Preoperative CTA and DSA showed a saccular aneurysm (arrow) on ACoA. C and D: The aneurysm neck was completely clipped by the pterional approach. 


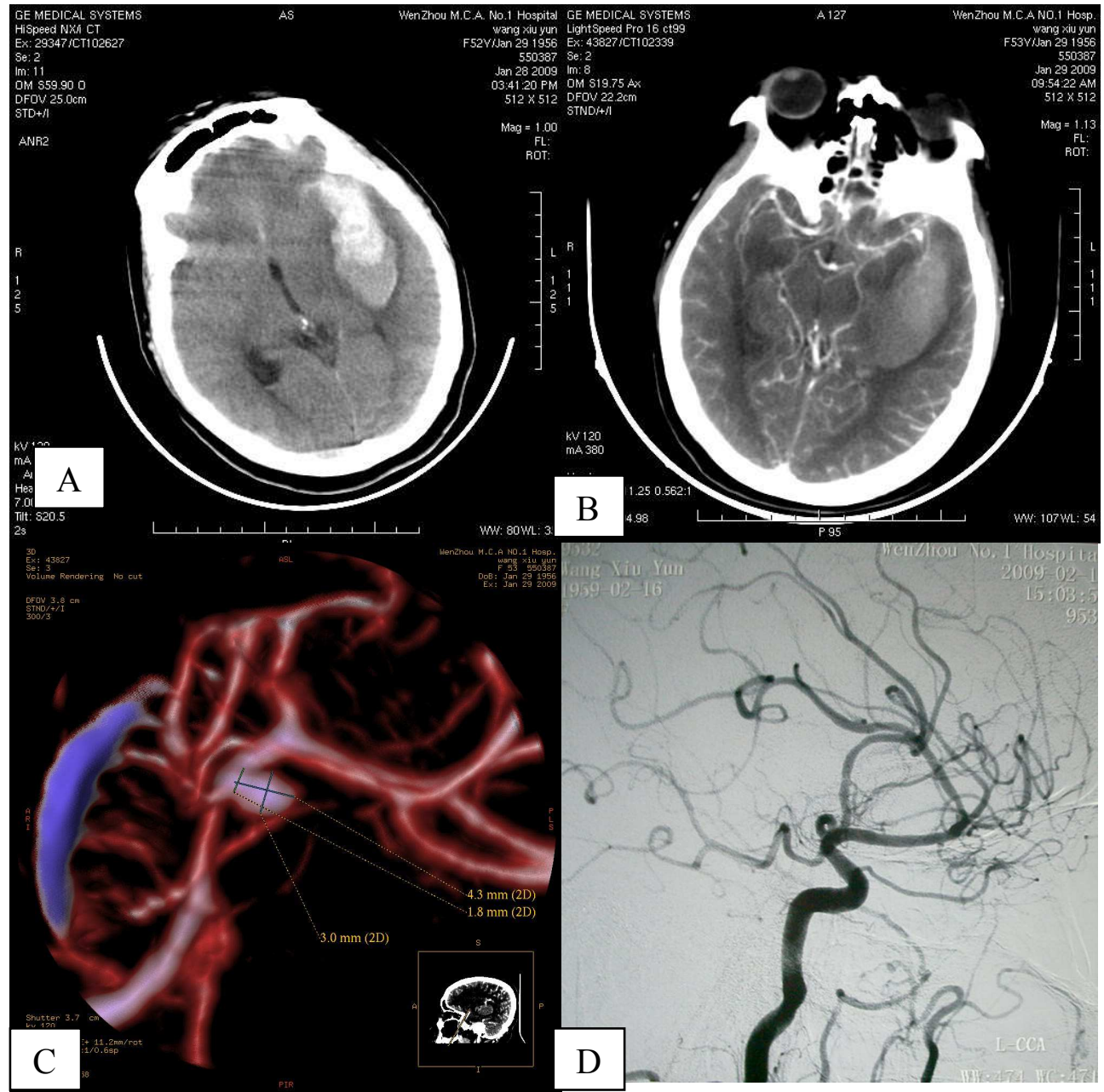

Fig. 2. Case 2: A. CT scan demonstrated a massive intracranial hematoma in the left temporal lobe B and C: CTA MIP and VR images demonstrated a saccular middle artery aneurysm surrounding the hematoma. D: DSA showed the complete occlusion of the aneurysm. 


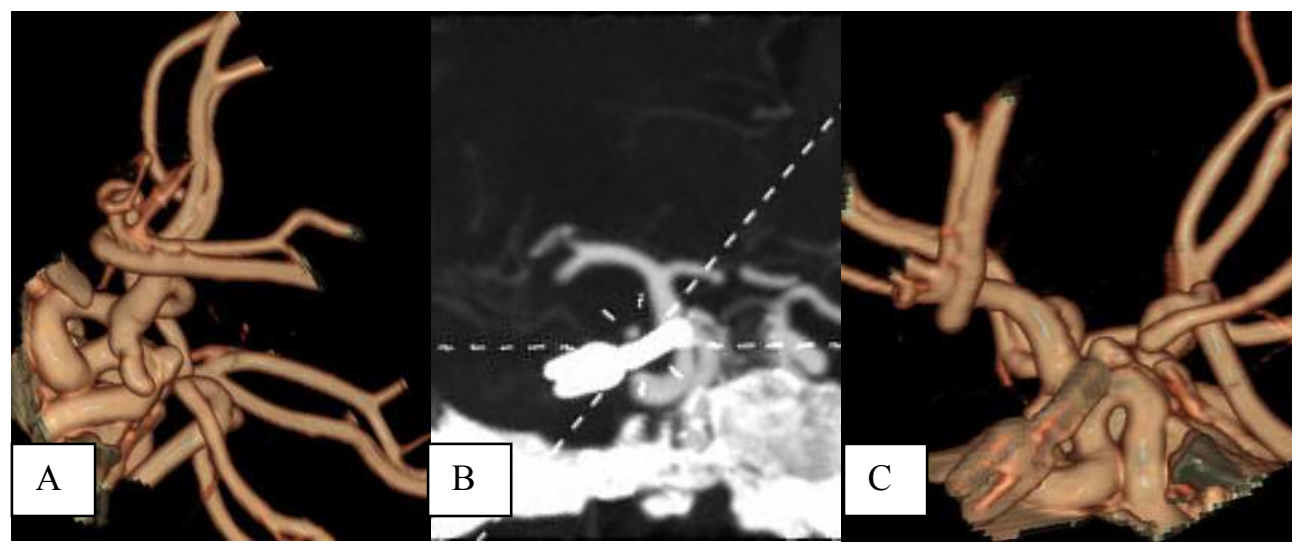

Fig. 3. Case 3: A: Preoperative CTA showed a saccular aneurysm on posterior communicating artery B and C: CTA MIP and VR images demonstrated the complete occlusion of the aneurysm .

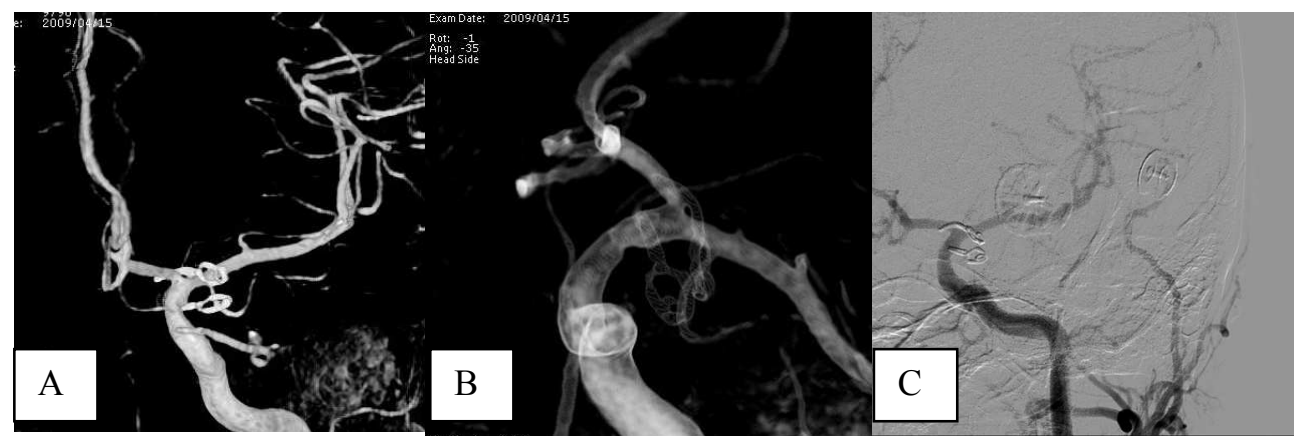

Fig. 4. Case 4: A and B: 3D-DSA was performed 7 days after surgical clipping completely C: The remnant of aneurysms were not visible on the 2D-DSA.

\section{Acknowledgments}

Funding for this chapter was from: Ministry of Health, China (20102-016); Department of Health, Zhejiang Province science funding (2008A142); Bureau of Science and Technology, Wenzhou (Y20090005).

\section{References}

[1] Bederson JB, Connolly ES, Jr., Batjer HH, Dacey RG, Dion JE, Diringer MN, Duldner JE, Jr., Harbaugh RE, Patel AB, Rosenwasser RH: Guidelines for the management of aneurysmal subarachnoid hemorrhage: a statement for healthcare professionals from a special writing group of the Stroke Council, American Heart Association. Stroke; a journal of cerebral circulation 2009, 40(3):994-1025.

[2] Brisman JL, Song JK, Newell DW: Cerebral aneurysms. The New England journal of medicine 2006, 355(9):928-939. 
[3] Ingall $\mathrm{T}$, Asplund $\mathrm{K}$, Mahonen M, Bonita R: A multinational comparison of subarachnoid hemorrhage epidemiology in the WHO MONICA stroke study. Stroke; a journal of cerebral circulation 2000, 31(5):1054-1061.

[4] van Gijn J, Rinkel GJ: Subarachnoid haemorrhage: diagnosis, causes and management. Brain 2001, 124(Pt 2):249-278.

[5] Al-Shahi R, White PM, Davenport RJ, Lindsay KW: Subarachnoid haemorrhage. BMJ (Clinical research ed 2006, 333(7561):235-240.

[6] Molyneux A, Kerr R, Stratton I, Sandercock P, Clarke M, Shrimpton J, Holman R: International Subarachnoid Aneurysm Trial (ISAT) of neurosurgical clipping versus endovascular coiling in 2143 patients with ruptured intracranial aneurysms: a randomised trial. Lancet 2002, 360(9342):1267-1274.

[7] Molyneux AJ, Kerr RS, Yu LM, Clarke M, Sneade M, Yarnold JA, Sandercock P: International subarachnoid aneurysm trial (ISAT) of neurosurgical clipping versus endovascular coiling in 2143 patients with ruptured intracranial aneurysms: a randomised comparison of effects on survival, dependency, seizures, rebleeding, subgroups, and aneurysm occlusion. Lancet 2005, 366(9488):809-817.

[8] Colby GP, Coon AL, Tamargo RJ: Surgical management of aneurysmal subarachnoid hemorrhage. Neurosurgery clinics of North America, 21(2):247-261.

[9] Molyneux AJ, Kerr RS, Birks J, Ramzi N, Yarnold J, Sneade M, Rischmiller J: Risk of recurrent subarachnoid haemorrhage, death, or dependence and standardised mortality ratios after clipping or coiling of an intracranial aneurysm in the International Subarachnoid Aneurysm Trial (ISAT): long-term follow-up. Lancet neurology 2009, 8(5):427-433.

[10] Butler WE, Barker FG, 2nd, Crowell RM: Patients with polycystic kidney disease would benefit from routine magnetic resonance angiographic screening for intracerebral aneurysms: a decision analysis. Neurosurgery 1996, 38(3):506-515; discussion 515506.

[11] Kojima M, Nagasawa S, Lee YE, Takeichi Y, Tsuda E, Mabuchi N: Asymptomatic familial cerebral aneurysms. Neurosurgery 1998, 43(4):776-781.

[12] Kissela BM, Sauerbeck L, Woo D, Khoury J, Carrozzella J, Pancioli A, Jauch E, Moomaw CJ, Shukla R, Gebel J et al: Subarachnoid hemorrhage: a preventable disease with a heritable component. Stroke; a journal of cerebral circulation 2002, 33(5):1321-1326.

[13] Wermer MJ, van der Schaaf IC, Algra A, Rinkel GJ: Risk of rupture of unruptured intracranial aneurysms in relation to patient and aneurysm characteristics: an updated meta-analysis. Stroke; a journal of cerebral circulation 2007, 38(4):1404-1410.

[14] Tulamo R, Frosen J, Laaksamo E, Niemela M, Laakso A, Hernesniemi J: [Why does the cerebral artery aneurysm rupture?]. Duodecim; laaketieteellinen aikakauskirja, 127(3):244-252.

[15] Hunt WE, Hess RM: Surgical risk as related to time of intervention in the repair of intracranial aneurysms. Journal of neurosurgery 1968, 28(1):14-20.

[16] Report of World Federation of Neurological Surgeons Committee on a Universal Subarachnoid Hemorrhage Grading Scale. Journal of neurosurgery 1988, 68(6):985986.

[17] Claassen J, Bernardini GL, Kreiter K, Bates J, Du YE, Copeland D, Connolly ES, Mayer SA: Effect of cisternal and ventricular blood on risk of delayed cerebral ischemia 
after subarachnoid hemorrhage: the Fisher scale revisited. Stroke; a journal of cerebral circulation 2001, 32(9):2012-2020.

[18] Hacein-Bey L, Connolly ES, Jr., Mayer SA, Young WL, Pile-Spellman J, Solomon RA: Complex intracranial aneurysms: combined operative and endovascular approaches. Neurosurgery 1998, 43(6):1304-1312; discussion 1312-1303.

[19] Hoh BL, Putman CM, Budzik RF, Carter BS, Ogilvy CS: Combined surgical and endovascular techniques of flow alteration to treat fusiform and complex widenecked intracranial aneurysms that are unsuitable for clipping or coil embolization. Journal of neurosurgery 2001, 95(1):24-35.

[20] Kremer C, Groden C, Hansen HC, Grzyska U, Zeumer H: Outcome after endovascular treatment of Hunt and Hess grade IV or V aneurysms: comparison of anterior versus posterior circulation. Stroke; a journal of cerebral circulation 1999, 30(12):26172622.

[21] Li MH, Li YD, Tan HQ, Gu BX, Chen YC, Wang W, Chen SW, Hu DJ: Contrast-free MRA at 3.0 $\mathrm{T}$ for the detection of intracranial aneurysms. Neurology.

[22] Hacein-Bey L, Provenzale JM: Current imaging assessment and treatment of intracranial aneurysms. Ajr, 196(1):32-44.

[23] Roth C: [Value of CT and MR angiography for diagnostics of intracranial aneurysms]. Der Radiologe, 51(2):106-112.

[24] Okahara M, Kiyosue H, Yamashita M, Nagatomi H, Hata H, Saginoya T, Sagara Y, Mori $\mathrm{H}$ : Diagnostic accuracy of magnetic resonance angiography for cerebral aneurysms in correlation with 3D-digital subtraction angiographic images: a study of 133 aneurysms. Stroke; a journal of cerebral circulation 2002, 33(7):1803-1808.

[25] Tan XX, Zhong M, Zheng K, Zhao B: Computed tomography angiography based emergency microsurgery for massive intracranial hematoma arising from arteriovenous malformations. Neurology India, 59(2):199-203.

[26] Velthuis BK, Rinkel GJ, Ramos LM, Witkamp TD, Berkelbach van der Sprenkel JW, Vandertop WP, van Leeuwen MS: Subarachnoid hemorrhage: aneurysm detection and preoperative evaluation with CT angiography. Radiology 1998, 208(2):423-430.

[27] Chen CY, Hsieh SC, Choi WM, Chiang PY, Chien JC, Chan WP: Computed tomography angiography in detection and characterization of ruptured anterior cerebral artery aneurysms at uncommon location for emergent surgical clipping. Clinical imaging 2006, 30(2):87-93.

[28] Westerlaan HE, van Dijk MJ, Jansen-van der Weide MC, de Groot JC, Groen RJ, Mooij JJ, Oudkerk M: Intracranial aneurysms in patients with subarachnoid hemorrhage: CT angiography as a primary examination tool for diagnosis--systematic review and meta-analysis. Radiology, 258(1):134-145.

[29] Velthuis BK, Van Leeuwen MS, Witkamp TD, Ramos LM, Berkelbach van Der Sprenkel JW, Rinkel GJ: Computerized tomography angiography in patients with subarachnoid hemorrhage: from aneurysm detection to treatment without conventional angiography. Journal of neurosurgery 1999, 91(5):761-767.

[30] Anxionnat R, Bracard S, Ducrocq X, Trousset Y, Launay L, Kerrien E, Braun M, Vaillant $\mathrm{R}$, Scomazzoni F, Lebedinsky A et al: Intracranial aneurysms: clinical value of 3D digital subtraction angiography in the therapeutic decision and endovascular treatment. Radiology 2001, 218(3):799-808. 
[31] Dyste GN BD: De novo aneurysm formation following carotid ligation: case report and review of the literature. Neurosurgery 1989, 24(1):88-92.

[32] Zhao Bing ZM, TAN Xian-xi, ZHENG Kuang, LI Jiang,ZHAO Jian-ting, CHENG Wei Surgical management of high-grade aneurysmal subarachnoid hemorrhage. Chinese Journal of Cenebrovascular Diseases 2010, 7(8):406-410.

[33] van Lindert E, Perneczky A, Fries G, Pierangeli E: The supraorbital keyhole approach to supratentorial aneurysms: concept and technique. Surgical neurology 1998, 49(5):481-489; discussion 489-490.

[34] Ramos-Zuniga R, Velazquez H, Barajas MA, Lopez R, Sanchez E, Trejo S: Transsupraorbital approach to supratentorial aneurysms. Neurosurgery 2002, 51(1):125130; discussion 130-121.

[35] Reisch R, Perneczky A, Filippi R: Surgical technique of the supraorbital key-hole craniotomy. Surgical neurology 2003, 59(3):223-227.

[36] Paladino J, Mrak G, Miklic P, Jednacak H, Mihaljevic D: The keyhole concept in aneurysm surgery--a comparative study: keyhole versus standard craniotomy. Minim Invasive Neurosurg 2005, 48(5):251-258.

[37] Lan Q, Chen J, Qian ZY, Zhang QB, Huang Q: [Microsurgical treatment of complex intracranial aneurysms via keyhole approaches]. Zhonghua yi xue za zhi 2007, 87(13):872-876.

[38] Perneczky A, Fries G: Endoscope-assisted brain surgery: part 1--evolution, basic concept, and current technique. Neurosurgery 1998, 42(2):219-224; discussion 224215.

[39] Profeta G, De Falco R, Ambrosio G, Profeta L: Endoscope-assisted microneurosurgery for anterior circulation aneurysms using the angle-type rigid endoscope over a 3year period. Childs Nerv Syst 2004, 20(11-12):811-815.

[40] Taniguchi M, Takimoto H, Yoshimine T, Shimada N, Miyao Y, Hirata M, Maruno M, Kato A, Kohmura E, Hayakawa T: Application of a rigid endoscope to the microsurgical management of 54 cerebral aneurysms: results in 48 patients. Journal of neurosurgery 1999, 91(2):231-237.

[41] Kalavakonda C, Sekhar LN, Ramachandran P, Hechl P: Endoscope-assisted microsurgery for intracranial aneurysms. Neurosurgery 2002, 51(5):1119-1126; discussion 1126-1117.

[42] Figueiredo EG, Foroni L, Monaco BA, Gomes MQ, Sterman Neto H, Teixeira MJ: The clip-wrap technique in the treatment of intracranial unclippable aneurysms. Arquivos de neuro-psiquiatria, 68(1):115-118.

[43] Solomon RA, Smith CR, Raps EC, Young WL, Stone JG, Fink ME: Deep hypothermic circulatory arrest for the management of complex anterior and posterior circulation aneurysms. Neurosurgery 1991, 29(5):732-737; discussion 737-738.

[44] Bailes JE, Tantuwaya LS, Fukushima T, Schurman GW, Davis D: Intraoperative microvascular Doppler sonography in aneurysm surgery. Neurosurgery 1997, 40(5):965-970; discussion 970-962.

[45] Cui H, Wang Y, Yin Y, Wan J, Fei Z, Gao W, Jiang J: Role of intraoperative microvascular Doppler in the microsurgical management of intracranial aneurysms. J Clin Ultrasound, 39(1):27-31.

[46] Raabe A, Nakaji P, Beck J, Kim LJ, Hsu FP, Kamerman JD, Seifert V, Spetzler RF: Prospective evaluation of surgical microscope-integrated intraoperative near- 
infrared indocyanine green videoangiography during aneurysm surgery. Journal of neurosurgery 2005, 103(6):982-989.

[47] Nanda A, Willis BK, Vannemreddy PS: Selective intraoperative angiography in intracranial aneurysm surgery: intraoperative factors associated with aneurysmal remnants and vessel occlusions. Surgical neurology 2002, 58(5):309-314; discussion 314-305.

[48] Gruber A, Dorfer C, Standhardt H, Bavinzski G, Knosp E: Prospective comparison of intraoperative vascular monitoring technologies during cerebral aneurysm surgery. Neurosurgery, 68(3):657-673; discussion 673.

[49] Cerejo A, Silva PA, Dias C, Vaz R: Monitoring of brain oxygenation in surgery of ruptured middle cerebral artery aneurysms. Surgical neurology international, 2:70.

[50] Kassell NF, Torner JC: Aneurysmal rebleeding: a preliminary report from the Cooperative Aneurysm Study. Neurosurgery 1983, 13(5):479-481.

[51] Ohkuma H, Tsurutani H, Suzuki S: Incidence and significance of early aneurysmal rebleeding before neurosurgical or neurological management. Stroke; a journal of cerebral circulation 2001, 32(5):1176-1180.

[52] Laidlaw JD, Siu KH: Poor-grade aneurysmal subarachnoid hemorrhage: outcome after treatment with urgent surgery. Neurosurgery 2003, 53(6):1275-1280; discussion 12801272.

[53] Naidech AM, Janjua N, Kreiter KT, Ostapkovich ND, Fitzsimmons BF, Parra A, Commichau C, Connolly ES, Mayer SA: Predictors and impact of aneurysm rebleeding after subarachnoid hemorrhage. Archives of neurology 2005, 62(3):410416.

[54] Rates of delayed rebleeding from intracranial aneurysms are low after surgical and endovascular treatment. Stroke; a journal of cerebral circulation 2006, 37(6):1437-1442.

[55] David CA, Vishteh AG, Spetzler RF, Lemole M, Lawton MT, Partovi S: Late angiographic follow-up review of surgically treated aneurysms. Journal of neurosurgery 1999, 91(3):396-401.

[56] Sloan MA, Alexandrov AV, Tegeler CH, Spencer MP, Caplan LR, Feldmann E, Wechsler LR, Newell DW, Gomez CR, Babikian VL et al: Assessment: transcranial Doppler ultrasonography: report of the Therapeutics and Technology Assessment Subcommittee of the American Academy of Neurology. Neurology 2004, 62(9):14681481.

[57] Suarez JI, Qureshi AI, Yahia AB, Parekh PD, Tamargo RJ, Williams MA, Ulatowski JA, Hanley DF, Razumovsky AY: Symptomatic vasospasm diagnosis after subarachnoid hemorrhage: evaluation of transcranial Doppler ultrasound and cerebral angiography as related to compromised vascular distribution. Critical care medicine 2002, 30(6):1348-1355.

[58] Egge A, Waterloo K, Sjoholm H, Solberg T, Ingebrigtsen T, Romner B: Prophylactic hyperdynamic postoperative fluid therapy after aneurysmal subarachnoid hemorrhage: a clinical, prospective, randomized, controlled study. Neurosurgery 2001, 49(3):593-605; discussion 605-596.

[59] Lennihan L, Mayer SA, Fink ME, Beckford A, Paik MC, Zhang H, Wu YC, Klebanoff LM, Raps EC, Solomon RA: Effect of hypervolemic therapy on cerebral blood flow after subarachnoid hemorrhage : a randomized controlled trial. Stroke; a journal of cerebral circulation 2000, 31(2):383-391. 
[60] Keyrouz SG, Diringer MN: Clinical review: Prevention and therapy of vasospasm in subarachnoid hemorrhage. Critical care (London, England) 2007, 11(4):220.

[61] Jestaedt L, Pham M, Bartsch AJ, Kunze E, Roosen K, Solymosi L, Bendszus M: The impact of balloon angioplasty on the evolution of vasospasm-related infarction after aneurysmal subarachnoid hemorrhage. Neurosurgery 2008, 62(3):610-617; discussion 610-617.

[62] Diringer MN: Management of aneurysmal subarachnoid hemorrhage. Critical care medicine 2009, 37(2):432-440.

[63] Cross DT, 3rd, Moran CJ, Angtuaco EE, Milburn JM, Diringer MN, Dacey RG, Jr.: Intracranial pressure monitoring during intraarterial papaverine infusion for cerebral vasospasm. Ajnr 1998, 19(7):1319-1323.

[64] Clouston JE, Numaguchi Y, Zoarski GH, Aldrich EF, Simard JM, Zitnay KM: Intraarterial papaverine infusion for cerebral vasospasm after subarachnoid hemorrhage. Ajnr 1995, 16(1):27-38.

[65] Macdonald RL, Wallace MC, Kestle JR: Role of angiography following aneurysm surgery. Journal of neurosurgery 1993, 79(6):826-832.

[66] el-Beltagy M, Muroi C, Roth P, Fandino J, Imhof HG, Yonekawa Y: Recurrent intracranial aneurysms after successful neck clipping. World neurosurgery, 74(45):472-477.

[67] ZHAOBing YH, LIU Jian,ZHONG Ming,TAN Xiang-xin,ZHANG Ming-sheng Value of three-dimensional CT angiography in postoperative evaluation of intracranial aneurysm clipping. Chinese Jounal of Neuromedicine 2009, 8(2):157-160.

[68] Zachenhofer I, Cejna M, Schuster A, Donat M, Roessler K: Image quality and artefact generation post-cerebral aneurysm clipping using a 64-row multislice computer tomography angiography (MSCTA) technology: A retrospective study and review of the literature. Clinical neurology and neurosurgery, 112(5):386-391.

[69] Kang HS, Han MH, Kwon BJ, Jung SI, Oh CW, Han DH, Chang KH: Postoperative 3D angiography in intracranial aneurysms. Ajnr 2004, 25(9):1463-1469.

[70] Ahn SS, Kim YD: Three-dimensional digital subtraction angiographic evaluation of aneurysm remnants after clip placement. Journal of Korean Neurosurgical Society, 47(3):185-190.

[71] Broderick JP, Brott TG, Duldner JE, Tomsick T, Leach A: Initial and recurrent bleeding are the major causes of death following subarachnoid hemorrhage. Stroke; a journal of cerebral circulation 1994, 25(7):1342-1347. 
EXPUCATIVE CASES OF

CONTROVERSIAL

ISSUES IN

NEUROSURGERY

tdiced by francescos simorell

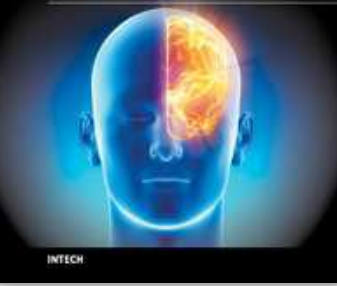

\section{Explicative Cases of Controversial Issues in Neurosurgery}

Edited by Dr. Francesco Signorelli

ISBN 978-953-51-0623-4

Hard cover, 534 pages

Publisher InTech

Published online 23, May, 2012

Published in print edition May, 2012

Neurosurgery is a rapidly developing field of medicine. Therefore, staying keeping track of the advancements in the field is paramount for trainees as well as fully trained neurosurgeons. This book, fully available online, is a part of our effort of improving availability of medical information for anyone who needs to keep up-to-date.

\section{How to reference}

In order to correctly reference this scholarly work, feel free to copy and paste the following:

Ming Zhong, Bing Zhao, Zequn Li and Xianxi Tan (2012). Ruptured Cerebral Aneurysms: An Update, Explicative Cases of Controversial Issues in Neurosurgery, Dr. Francesco Signorelli (Ed.), ISBN: 978-953-510623-4, InTech, Available from: http://www.intechopen.com/books/explicative-cases-of-controversial-issues-inneurosurgery/ruptured-cerebral-aneurysms-an-update

\section{INTECH}

open science | open minds

\section{InTech Europe}

University Campus STeP Ri

Slavka Krautzeka 83/A

51000 Rijeka, Croatia

Phone: +385 (51) 770447

Fax: +385 (51) 686166

www.intechopen.com

\section{InTech China}

Unit 405, Office Block, Hotel Equatorial Shanghai

No.65, Yan An Road (West), Shanghai, 200040, China

中国上海市延安西路65号上海国际贵都大饭店办公楼405单元

Phone: +86-21-62489820

Fax: +86-21-62489821 
(C) 2012 The Author(s). Licensee IntechOpen. This is an open access article distributed under the terms of the Creative Commons Attribution 3.0 License, which permits unrestricted use, distribution, and reproduction in any medium, provided the original work is properly cited. 